\title{
Combined effect of short stature and socioeconomic status on body mass index and weight gain during reproductive age in Brazilian women
}

\author{
R. Sichieri ${ }^{1}$, \\ C.V.C. Silva ${ }^{2}$ \\ and A.S. Moura ${ }^{3}$
}

Institutos de ${ }^{1}$ Medicina Social, ${ }^{2}$ Nutrição, and

${ }^{3}$ Biologia, Universidade Estadual do Rio de Janeiro,

Rio de Janeiro, RJ, Brasil

\section{Correspondence}

A.S. Moura

Laboratório de Fisiologia da

Nutrição e do Desenvolvimento

Departamento de Ciências

Fisiológicas, IB, UERJ

Av. 28 de setembro, 87 fundos

20550-030 Rio de Janeiro, RJ

Brasil

Fax: +55-21-2587-6129

E-mail: asmoura@uerj.br

$\ldots \ldots \ldots \ldots \ldots \ldots$

Received November 25, 2002 Accepted June 23, 2003

\begin{abstract}
Short stature, a marker for undernutrition early in life, has been associated with obesity in Brazilian women, but not in men. We tested the hypothesis that weight gain during the reproductive years could explain this gender difference. A national two-stage household survey of mothers with one or more children under five years of age was conducted in Brazil in 1996. The subjects were women aged 20 to 45 years $(\mathrm{N}=2297)$, with last delivery seven months or more prior to the interview. The regions of the country were divided into rural, North/ Northeast (urban underdeveloped) and South/Southeast/Midwest (urban developed). The dependent variables were current body mass index (BMI) measured, BMI prior to childbearing (reported), and BMI change. Socioeconomic variables included mother's years of education and family purchasing power score. A secondary analysis was restricted to primiparous women. The prevalence of current overweight and overweight prior to childbearing (BMI $\geq 25 \mathrm{~kg} / \mathrm{m}^{2}$ ) was higher among shorter women $(<1.50 \mathrm{~m})$ compared to normal stature women only in the urban developed region $(\mathrm{P}<0.05)$. After adjustment for socioeconomic variables, age, parity, BMI prior to childbearing, and age at first birth, current BMI was 2.39 units higher $(\mathrm{P}=$ 0.008 ) for short stature women living in the urban developed area compared with short stature women living in the urban underdeveloped area. For both multiparous and primiparous women, BMI gain compared to the value prior to childbearing was significantly higher among short stature women living in the urban developed region $(\mathrm{P} \leq$ 0.04). These results provide clear evidence that short stature was associated with a higher BMI and with an increased risk of weight gain/retention with pregnancy in the developed areas of Brazil, but not in the underdeveloped ones.
\end{abstract}

Key words - Parity - Body mass index - Weight gain - Pregnancy - Overweight - Stature 


\section{Introduction}

Undernutrition early in life has been associated with obesity among children and adults in some (1-6), but not all, studies (79). Short stature, a marker of early poor nutrition, was associated with obesity and abdominal fatness among women, but not among men in two population-based surveys in Brazil $(6,10)$. Reproductive factors are a plausible explanation for this gender difference in the association between short stature and obesity. Parity has been positively associated with weight gain and with the onset of obesity in population-based studies in developed countries (11-16), and also in Brazil, as shown by a previous analysis of the III Brazilian Demographic and Health Survey (DHS96) (17). Events during the fetal and early postnatal growth period by causing permanent metabolic alterations through adult life may facilitate maternal fat deposition during pregnancy. Thus, low birth weight has been linked to adult glucose intolerance $(18,19)$, and to activation of the cortisol axis during adult life (20,21). These metabolic changes due to insulin or cortisol could drive a greater fat deposition among short stature pregnant women. Therefore, in a sample of parous women we determined whether weight gain during the reproductive years increases the prevalence of obesity/overweight in women of short stature, and whether this association varies in different regions of Brazil. By design, this survey did not include nulliparous women. In order to better differentiate the effects of childbearing from underlying secular trends and aging on weight change a secondary analysis included only primiparous women.

\section{Subjects and Methods}

\section{Study population}

The III DHS was conducted in 1996. A full description of the survey sampling frame can be found elsewhere $(17,22)$. This was a nationwide, two-stage probability sampling survey that included only women with one or more children under five years of age. The response rate for households was $80.9 \%$. The population eligible for the current analysis consisted of the 2368 parous women surveyed in the III DHS aged 20 to 45 years at the time of the interview after excluding pregnant women at the time of the survey (285 women), women who reported delivery seven months before or less at the time of the interview (621 women), first birth before the age of 15 (199 women; since they could have gained height since their first pregnancy interfering with the calculations of the prior body mass index, BMI). Also excluded were 41 women whose weight or stature values were missing and 30 with improbable values (stature $<130 \mathrm{~cm}$ or weight $<35 \mathrm{~kg}$ ). The final study sample size was 2297 women.

\section{Measurement of the variables}

The dependent variable, current BMI (weight $/$ height $^{2}$, in $\mathrm{kg} / \mathrm{m}^{2}$ ), was calculated from weight and height measurements taken in the household by two trained interviewers. Weight before childbearing was recalled at the end of the 30-min interview (22). Weight was measured using Seca-UNICEF 890 microelectronic scales with lithium batteries, and height using Stanley anthropometric tapes. Anthropometrists were trained and standardized and quality control was carried out during fieldwork supervision. The technical error for stature was equal to $0.23 \mathrm{~cm}$. Short stature was defined as the 5 th percentile of the US population $(150 \mathrm{~cm})$ (23).

Purchasing power score as used by the Brazilian Association of Marketing Research is a combined score of highest level of education obtained by the family, with services and items available in the house such as housemaid, number of radios, VCRs, televisions, refrigerators, etc. $(17,22)$. Regions of 
the country were divided into three categories: rural, urban area of the North/Northeast, which is the least developed region of the country, and the third region combining the urban areas of the South, Southeast, and Midwest, which are more developed regions. Throughout the text these three regions are called rural, urban underdeveloped and urban developed regions, respectively. Parity is the number of live births and stillbirths of each woman and education is the total number of completed formal years of education.

\section{Analytical procedures}

Means and percentages were weighted to reflect national estimates. In order to account for the variance associated with sampling, we used the "Proc surveyreg" procedure of the Statistical Analysis System (SAS). We regressed short stature on weight prior to childbearing, current weight, and weight change from prior to childbearing to current weight. Models included age, socioeconomic, geographic, and reproductive variables. When weight gain and current BMI were the dependent variables, BMI prior to childbearing was included in the model, since previous analysis of these data as well as data from other studies indicate that high BMI prior to childbearing is the most important predictor of weight gain associated with reproduction. In addition, since parity and short stature are highly associated with socioeconomic factors, we included in the models markers for socioeconomic level (purchasing power score and women's years of education). Plausible interactions between the co-variables and stature were tested jointly. Second-order terms were tested for age and parity (number of live births and stillbirths). The exclusion criterion for interaction and second-term variables was a $\mathrm{P}$ value $>0.05$. Both BMI and weight change were log transformed to normalize the data. To permit log transformation of weight change, the smallest negative weight difference was added to each weight change value. The analysis compared the risk of overweight and obesity by measuring prevalence ratios.

\section{Results}

The prevalence of current overweight and obesity (BMI $\geq 25 \mathrm{~kg} / \mathrm{m}^{2}$ ) was higher among short stature women living in the urban developed region of the country compared to short stature women living in rural or urban underdeveloped areas (Table 1). Among women living in the urban developed region the risk of overweight or obesity (BMI $\geq 25$ $\mathrm{kg} / \mathrm{m}^{2}$ ) was 1.27 (46.0 vs 36.2\%) when short stature women were compared to normal stature women. Prior to childbearing, overweight and obesity rates were higher among short stature women in all regions, although prevalences were much lower and differences according to stature were statistically significant only for the urban developed region (Table 1).

The prevalence of short stature was $23.9 \%$ in the rural area, $21.7 \%$ in the urban underdeveloped area, and $10.1 \%$ in the urban developed area.

Parity was significantly different in the three regions studied, with the highest parity level being observed in the rural area (Table 2 ). For most of the socioeconomic variables, statistically significant differences were found between the urban developed region and the urban underdeveloped region (Table 2).

After adjustment for age, reproductive factors and socioeconomic variables, current BMI was 2.39 units $(0.86+1.72-0.19)$ higher among short stature women living in the urban developed area compared to normal stature women living in the urban underdeveloped region (Table 3). Yet the $\beta$ regression coefficient for the urban developed area $(-0.19)$ was not statistically significant. Region was included in the model as two indicator variables with urban developed region as the reference group; therefore, for effect estimation both indicator variables and 
interaction terms were considered.

Thus, region of the country is a strong modifier of the association between short stature and BMI. In these multivariate models parity, previous BMI and age were important predictors of current BMI $(\mathrm{P}<0.01)$ (data not shown). Table 3 also shows that, when analysis was restricted to primiparous women allowing a better control of cohort effect, the interaction term in the current $\mathrm{BMI}$ model was no longer significant $(\mathrm{P}=$
0.07). However, overall models for BMI prior to childbearing and BMI change involved the same interpretation as the models including all women, with the same pattern and magnitude of association.

\section{Discussion}

In 1996, about $50 \%$ of Brazilian parous women living in the urban developed area and with stature shorter than $1.50 \mathrm{~m}$ were

Table 1. Prevalence of overweight and obesity by stature among parous women in three regions of Brazil, 1996.

\begin{tabular}{|c|c|c|c|c|c|c|}
\hline & \multicolumn{2}{|c|}{ Rural } & \multicolumn{2}{|c|}{$\begin{array}{c}\text { Urban } \\
\text { underdeveloped }\end{array}$} & \multicolumn{2}{|c|}{$\begin{array}{c}\text { Urban } \\
\text { developed }\end{array}$} \\
\hline & Short & Normal & Short & Normal & Short & Normal \\
\hline Current BMI & $(N=116)$ & $(\mathrm{N}=370)$ & $(\mathrm{N}=179)$ & $(N=645)$ & $(N=100)$ & $(N=887)$ \\
\hline Overweight - BMI 25.0-29.9 & 25.0 & 23.0 & 23.5 & 24.3 & 34.0 & 26.6 \\
\hline Obesity - BMI $\geq 30.0$ & 11.2 & 10.3 & 6.1 & 8.0 & 12.0 & 9.6 \\
\hline Both $\mathrm{BMI}>25.0$ & 36.2 & 33.3 & 29.6 & 32.3 & 46.0 & 36.2 \\
\hline$\chi^{2} \mathrm{P}$ value $(\mathrm{BMI}<25 / \geq 25)$ & \multicolumn{2}{|c|}{0.56} & \multicolumn{2}{|c|}{0.47} & \multicolumn{2}{|c|}{0.05} \\
\hline BMI prior to childbearing & $(N=85)$ & $(N=288)$ & $(N=147)$ & $(N=567)$ & $(N=83)$ & $(\mathrm{N}=832)$ \\
\hline Overweight - BMI 25.0-29.9 & 14.2 & 13.5 & 10.9 & 9.88 & 22.8 & 9.6 \\
\hline Obesity - BMI $\geq 30.0$ & 5.88 & 0.69 & 2.72 & 1.06 & 2.41 & 1.56 \\
\hline Both $\mathrm{BMI}>25.0$ & 20.0 & 14.2 & 13.6 & 10.9 & 25.3 & 11.1 \\
\hline$\chi^{2} \mathrm{P}$ value $(\mathrm{BMI}<25 / \geq 25)$ & \multicolumn{2}{|c|}{0.20} & \multicolumn{2}{|c|}{0.33} & \multicolumn{2}{|c|}{0.002} \\
\hline Weight gain $(\mathrm{kg})$ & 4.92 & 5.97 & 2.89 & $6.27^{*}$ & 6.73 & 6.32 \\
\hline Relative weight gain (BMI units) & 2.30 & 2.42 & 1.34 & $2.53^{*}$ & 3.09 & 2.53 \\
\hline
\end{tabular}

$\mathrm{BMI}=$ body mass index $\left(\mathrm{kg} / \mathrm{m}^{2}\right)$. BMI data are reported as percent.

${ }^{*} P<0.05$ comparing short and normal stature women within each region (Student $t$-test).

Table 2. Age, age-adjusted means and standard deviation (SD) of body mass index (BMI, $\mathrm{kg} / \mathrm{m}^{2}$ ), weight gain and reproductive and socioeconomic variables among parous women in three regions of Brazil, 1996.

\begin{tabular}{lcrr}
\hline & Rural & Urban underdeveloped & Urban developed \\
\hline Age (years) & $29.9 \pm 6.3^{\mathrm{a}}$ & $28.4 \pm 5.5^{\mathrm{b}}$ & $29.5 \pm 5.7^{\mathrm{a}}$ \\
Current BMI & $23.6 \pm 4.3^{\mathrm{a}}$ & $23.7 \pm 4.0^{\mathrm{a}}$ & $24.3 \pm 4.2^{\mathrm{b}}$ \\
BMI prior to childbearing & $21.7 \pm 3.5^{\mathrm{a}, \mathrm{b}}$ & $21.3 \pm 3.3^{\mathrm{a}}$ & $21.7 \pm 3.2^{\mathrm{b}}$ \\
Weight gain (kg) & $5.2 \pm 9.4^{\mathrm{a}}$ & $5.6 \pm 8.5^{\mathrm{a}}$ & $6.4 \pm 8.8^{\mathrm{b}}$ \\
Height (m) & $1.54 \pm 0.064^{\mathrm{a}}$ & $1.55 \pm 0.064^{\mathrm{a}}$ & $1.58 \pm 0.062^{\mathrm{b}}$ \\
Purchasing power score & $16.3 \pm 15.5^{\mathrm{a}}$ & $16.1 \pm 14.3^{\mathrm{a}}$ & $26.6 \pm 15.9^{\mathrm{b}}$ \\
Education (years) & $2.9 \pm 1.5^{\mathrm{a}}$ & $3.8 \pm 2.0^{\mathrm{b}}$ & $3.9 \pm 1.9^{\mathrm{b}}$ \\
Age at first birth (years) & $21.0 \pm 3.6^{\mathrm{a}}$ & $21.4 \pm 4.3^{\mathrm{a}}$ & $22.4 \pm 4.6^{\mathrm{b}}$ \\
Parity & $3.4 \pm 2.3^{\mathrm{a}}$ & $2.7 \pm 1.9^{\mathrm{b}}$ & $2.2 \pm 1.4^{\mathrm{c}}$ \\
& & & \\
\hline Data are reported as means \pm SD. & & &
\end{tabular}


Table 3. Regression coefficients ( $($ ) of multivariate linear regression of short stature on body mass index (BMI) in three different models adjusted for the main confounding variables (Brazil, 1996).

\begin{tabular}{|c|c|c|c|c|c|c|}
\hline \multirow[t]{3}{*}{ Parameter } & \multicolumn{6}{|c|}{ All women $(N=1931)$} \\
\hline & \multicolumn{2}{|c|}{ Current BMI* } & \multicolumn{2}{|c|}{ Pre-pregnancy BMI** } & \multicolumn{2}{|c|}{ BMI change *** } \\
\hline & B & $P$ value & B & $P$ value & B & $P$ value \\
\hline Stature $(<1.50 / 1.50)$ & 0.86 & 0.02 & 0.66 & 0.04 & -1.13 & 0.001 \\
\hline \multicolumn{7}{|l|}{ Region } \\
\hline Rural & -0.002 & 0.99 & 0.50 & 0.09 & -0.19 & 0.60 \\
\hline Urban underdeveloped & 0 & (reference) & 0 & (reference) & 0 & (reference) \\
\hline Urban developed & -0.19 & 0.39 & 0.48 & 0.02 & -0.16 & 0.40 \\
\hline Stature*Rural & 0.72 & 0.35 & -0.26 & 0.68 & 0.86 & 0.21 \\
\hline Stature*Developed & 1.72 & 0.008 & 0.12 & 0.81 & 1.50 & 0.02 \\
\hline \multirow[t]{4}{*}{$\mathrm{R}^{2}$} & \multicolumn{2}{|r|}{0.29} & \multicolumn{2}{|c|}{0.02} & \multicolumn{2}{|c|}{0.06} \\
\hline & \multicolumn{6}{|c|}{ Primiparous women ( $N=622$ ) } \\
\hline & \multicolumn{2}{|c|}{ Current BMI* } & \multicolumn{2}{|c|}{ Pre-pregnancy BMI** } & \multicolumn{2}{|c|}{ BMl change ${ }^{* * *}$} \\
\hline & B & $P$ value & B & $P$ value & B & $P$ value \\
\hline Stature $(<1.50 / 1.50)$ & 1.39 & 0.002 & 0.77 & 0.07 & -0.77 & 0.04 \\
\hline \multicolumn{7}{|l|}{ Region } \\
\hline Rural & -0.39 & 0.23 & 0.43 & 0.28 & -0.50 & 0.09 \\
\hline Urban underdeveloped & 0 & (reference) & 0 & (reference) & 0 & (reference) \\
\hline Urban developed & 0.50 & 0.05 & 0.65 & 0.06 & 0.49 & 0.03 \\
\hline Stature*Rural & 1.12 & 0.25 & -0.48 & 0.75 & 1.05 & 0.19 \\
\hline Stature*Developed & 1.50 & 0.07 & -0.73 & 0.43 & 1.46 & 0.04 \\
\hline$R^{2}$ & \multicolumn{2}{|r|}{0.56} & \multicolumn{2}{|c|}{0.02} & \multicolumn{2}{|c|}{0.04} \\
\hline
\end{tabular}

* Models adjusted for age, age squared, purchasing power score, years of education, BMI before childbearing, mother's age at birth, and parity. ${ }^{*}$ All previous variables except for BMI prior to childbearing, mother's age at birth and parity. ${ }^{* *}$ All previous variables except for BMI prior to childbearing.

overweight or obese. Women with such stature in this region had a higher prevalence of overweight $(\mathrm{RR}=1.27)$ than their counterparts with normal stature, but for the other two regions (rural and urban North/Northeast) short stature was not associated with BMI. This association was unchanged after adjustment for demographic and socioeconomic factors. This modification of region effect on the association between stature and BMI was not observed for BMI prior to childbearing (stature*rural and stature*developed terms had $\mathrm{P}$ values $>0.60$ ), after adjusting for socioeconomic factors. However, short stature and living in the urban region were predictors of BMI prior to childbearing
$(\mathrm{P}<0.05)$. Thus, short stature, a marker for undernutrition during childhood, appears to be related to higher BMI prior to childbearing in all regions and also to weight gain after pregnancy in the more developed region of the country. Analysis including only primiparous women showed the greatest BMI change with short stature in the urban developed region $(+0.49+1.46=1.95$ units of BMI). These findings support the hypothesis of preferential weight gain, or weight retention with pregnancy associated with short stature and may contribute to understanding the gender effect of short stature on BMI, as shown in two Brazilian studies which found a risk of greater BMI and waist-hip ratio 
among short stature women, but not among men (6-10).

Also interesting is the lack of association between short stature and current BMI in the rural and the underdeveloped areas of the country. This important interaction, at least in this population, suggests that the health/ nutritional transition may modify the effect of early exposures, such as undernutrition, on chronic diseases. Our data may indicate that a minimum of food availability or the kind of food availability present in urban centers would be required for the expression of a metabolic programming at an early age.

It should be noted that the five regions of the country, North, Northeast, South, Southeast and Midwest, have special dietary and lifestyle habits. However, other anthropometric studies have shown that these regions, as clustered into rural, urban developed and urban underdeveloped regions in the present study, are important predictors of obesity (24).

In a previous study of Brazilian women we showed that the association between stature and overweight was not due to limitations of using BMI as an indicator of obesity, or to possible bias due to the persistence in adult life of socioeconomic conditions which produced the effects attributed to programming (10). In the present study we found an association of both current BMI and weight gain (BMI change) with short stature, but this association persisted after controlling for socioeconomic factors only in the more developed area of the country. Under the hypothesis of an incomplete control of confounding for socioeconomic condition operating in this population we would expect a greater association between stature and obesity in rural and underdeveloped urban areas, which had the lowest socioeconomic levels. However, after adjustment for socioeconomic factors there was no association in these areas. This finding of a statistical interaction between area of the country and stature may indicate that a western life style, such as that present in metropolitan areas of developing countries, may contribute to the manifestation of a metabolic programming early in life.

Although there was no confirmation of pre-childbearing weight other than the recall, as an attempt to validate the recalled pre-pregnancy weight we compared the recalled BMI distribution of the 21- to 29year-old women in our study with a measured BMI distribution of nulliparous women from a national survey. There was a good consistency in the percentile distributions as we presented in a previous paper (17).

In agreement with other studies we found that BMI prior to childbearing was the most important predictor of recent BMI $(12,14$, 16,17). Population-based follow-up analysis of the United States population (NHANES I follow-up) showed that women with high BMI had an increased risk of greater weight gain with parity (21).

Adult short stature has been related to glycemia $(18,19)$, insulin (13) and cortisol levels $(21,22)$. Changes in insulin sensitivity during pregnancy increase fat deposition (25) and may explain how environmental conditions that allow marginal adequacy of energy intake may favor metabolic changes directed to fat deposition. These hormonal changes could explain how small increases in food availability are associated with a large increase in the prevalence of obesity. Energy intake and fat intake did not explain the association between short stature and obesity in a Brazilian population-based survey (10). 


\section{References}

1. Ravelli GP, Stein ZA \& Susser MW (1976). Obesity in young men after famine exposure in utero and early infancy. New England Journal of Medicine, 295: 349-353.

2. Sichieri R, Mathias T \& Moura AS (1996). Stunting, high weight-forheight, anaemia and dietary intake among Brazilian students from a rural community. Nutrition Research, 16: 201-209.

3. Popkin BM, Richards MK \& Monteiro CA (1996). Stunting associated with overweight in children of four nations that are undergoing the nutrition transition. Journal of Nutrition, 126: 3009-3016.

4. Martorell R, Mendoza FS, Castilho RO, Pawson IG \& Budge CC (1987). Short and plump physique of Mexican-American children. American Journal of Physical Anthropology, 73: 475-478.

5. Soares-Wynter SY \& Walker SP (1996). Resting metabolic rate and body composition in stunted and nonstunted children. American Journal of Clinical Nutrition, 64: 137-141.

6. Velasquez-Melendez G, Martins IS, Cervato AM, Fornes NS, Marucci MF \& Coelho LT (1999). Relationship between stature, overweight and central obesity in the adult population in São Paulo, Brazil. International Journal of Obesity and Related Metabolic Disorders, 23: 639-644.

7. Han TS, McNeill G, Seidel JC \& Lean MEJ (1997). Predicting intraabdominal fatness from anthropometric measures: the influence of stature. International Journal of Obesity, 21: 587-593.

8. Curhan CG, Willett WC, Rimm EB, Spiegelman D, Ascherio AL \& Stamper MJ (1996). Birth weight and adult hypertension, diabetes mellitus, and obesity in USA men. Circulation, 94: 1310-1315.

9. Valdez R, Athens MA, Thompson GH, Bradshaw BS \& Stern MP (1994). Birthweight and adult health outcomes in a biethnic population in the USA. Diabetologia, 37: 624-631.

10. Sichieri R, Siqueira KS \& Moura AS (2000). Obesity and abdominal fatness associated with undernutrition early in life in a survey in Rio de Janeiro. International Journal of Obesity and Related Metabolic Disorders, 24: 614-618.

11. Gunderson EP \& Abrams B (2000). Epidemiology of gestational weight gain and body weight changes after pregnancy. Epidemiological Reviews, 22: 261-274

12. Wolf WS, Sobal J, Olson CM \& Frongillo EA (1997). Parity-associated body weight: modification by socio-demographic and behavioral factors. Obesity Research, 5: 131-141.

13. Smith DE, Lewis CE, Caveny JL, Perkins LL, Burke GL \& Bild DE (1994). Longitudinal changes in adiposity associated with pregnancy - the CARDIA study. Journal of the American Medical Associa- tion, 271: 1747-1751

14. Williamson DF, Madans J, Pamuk E, Flegal KM, Kendrick JS \& Serdula MK (1994). A prospective study of childbearing and 10-year weight gain in US white women 25 to 45 years of age. International Journal of Obesity, 18: 561-569.

15. Brown JE, Kaye AS \& Folsom AR (1992). Parity related weight change in women. International Journal of Obesity, 16: 627-631.

16. Ohlin A \& Rossner S (1990). Maternal body weight development after pregnancy. International Journal of Obesity, 14: 159-173.

17. Coitinho DC, Sichieri R \& D'Aquino Benício ME (2001). Obesity and weight change related to parity and breast-feeding among parous women in Brazil. Public Health Nutrition, 4: 865-870.

18. Brown DC, Byrne CD, Clark PM, Cox BD, Day NE, Hales CN, Shackleton JR, Wang TW \& Williams DR (1991). Height and glucose tolerance in adult subjects. Diabetologia, 34: 531-533.

19. Lithell HO, McKeigue PM, Berglund L, Mohsen R, Lithell UB \& Leon DA (1996). Relation of size at birth to non-insulin dependent diabetes and insulin concentrations in men aged $50-60$ years. British Medical Journal, 312: 406-410

20. Levitt NS, Lambert EV, Woods D, Hales CN, Andrew R \& Seckl JR (2000). Impaired glucose tolerance and elevated blood pressure in low birth weight, nonobese, young South African adults: early programming of cortisol axis. Journal of Clinical Endocrinology and Metabolism, 85: 4611-4618.

21. Welberg LAM \& Seckl JR (2000). Prenatal stress, glucocorticoids and the programming of the brain. Journal of Neuroendocrinology, 13: 113-128.

22. BEMFAM (1997). Pesquisa Nacional sobre Demografia e Saúde, DHS/III. BEMFAM e MACRO International, Rio de Janeiro, RJ, Brazil.

23. National Center for Health Statistics (1987). Anthropometric reference data and prevalence of overweight. United States 1976-1980. DHHS Publication No. 87-1688. US Department of Health and Human Services, Hyattsville, MD, USA.

24. Sichieri R, Coitinho DC, Leão MM, Recine E \& Everhart JE (1994). High temporal, geographic, and income variation in body mass index among adults in Brazil. American Journal of Public Health, 84: 793-798.

25. Catalano PM (1999). Pregnancy and lactation in relation to range of acceptable carbohydrate and fat intake. European Journal of Clinical Nutrition, 53 (Suppl 1): S124- S131. 